\title{
Limiting Long term illness and informal care: Experiences of older people in Sylhet city, Bangladesh
}

\author{
Professor Muhammed Muazzam Hussain \\ Dept. of Social Work \\ Shahjalal University of Science \& Technology, Sylhet, Bangladesh \\ Mail: muazzam777@yahoo.com \\ Cell: +88 01716562079
}

DOI: 10.31364/SCIRJ/v7.i11.2019.P1119729

http://dx.doi.org/10.31364/SCIRJ/v7.i11.2019.P1119729

\begin{abstract}
This study aimed to explore the experiences of informal care services received by older people with long term illness (LLTI) living in the Sylhet region of Bangladesh. The study was conducted using the qualitative research approach and both purposive and snowball sampling methods were used to gain easy access to the respondents. The semi-structured interviews of twenty one (21) samples and two (02) focus group discussion (FGDs) were arranged with six to eight participants in each group to generate sufficient primary data and address the research objectives. The study findings highlight the fact that older people with LLTI experiences multiple disadvantages in terms of ill health, poverty and other socio-cultural factors. It is evident from the study that the traditional aspect of family caring is facing challenges e.g. strain relationship with informal carers, differences in choice of food, etc. The study findings also reveal that family's ability to provide care has been also contracted for a number of reasons including poverty of the family, death of spouse, inappropriate housing condition, high cost of treatment etc. The study points out some potential source of tension and strain relationship which creates potential risk of older neglect and abuse inside the family.
\end{abstract}

Keywords: Limiting long term illness, informal care, older people, Bangladesh

\section{Background to the study}

Bangladesh has experienced a massive growth of older people due to the improvement in health and other development indicators such as life expectancy. According to the National Population Census of Bangladesh (2011), it is revealed that the aggregate number of the older population above 65 years of age stands at 47, 61, 700 persons. Old age is associated with some special needs in terms of health, personal care, and psychological and emotional support. However, inadequate health care facilities and widespread poverty increase the sufferings of older people in most of the developing countries including Bangladesh. The older people have traditionally been enjoying a respected position in the Bangladeshi social structure from time immemorial as the guardian, primary decision makers and are often consulted as advisors at the family and the community. Therefore, families used to take all the responsibility of older members including their caring needs. Bangladeshi cultural norms and religious values obliged children to look after their parents in the old age (Victor \& Zubair, 2015; Gardner, 2002). The culture of reciprocity in caregiving is a significant source of social security for the older people in Bangladesh. The traditional joint families, caste system, and village panchayat have been providing www.scirj.org 
major services to the aged people in Bangladesh due to the limited number of formal services. But, the recent changes in demography and urbanization also create some changes in informal care provision for the older people living in urban areas including breaking down of joint families, family based support to older people and their relationship with family members. Therefore, it is worthily to investigate the informal caring of the older people in Bangladesh with long term illness.

\section{Literature review}

Very few researches have been conducted to address the issue in the current context of Bangladesh. Some important studies were conducted with Bangladeshi older people in UK which suggest that older people receive both intra-generational and inter-generational caring in the family. As such, the vast majority of 'informal care' to them are provided by the spouse and adult children irrespective of ethnicity in the UK (Victor \& Zubair, 2015). Typically, intra-generational care is mostly provided by the spouse while the children, grandchildren, and nieces provide extra-generational care and support. A recent study (Victor \& Zubair, 2015) in the UK with Bangladeshi and Pakistani older males and females illustrated the dependency of men on their wives in case of care needs. Wives provided care and support to their spouse because of social norms and religious obligation. The study highlighted the dependency of older Bangladeshi people on the family for care and support needs. Bangladeshi parents living in the UK perceive their adult children as a key source of future care and support. Some of the parents are confident that their children will look after them in their old age (Victor, Martin, \& Zubair, 2012; Victor \& Zubair, 2015).

Research evidences (Purewal \& Jasani, 2017; Victor \& Zubair, 2015) suggest the availability of informal support for older adults in South Asian countries as they feel comfortable to be supported and cared of by their family members instead of the professional carers. This feeling has been promoted and nurtured by the collectivist social norms, religious obligation, and cultural practices. By contrast, critiques argue that regular contact with family members or friends does not necessarily indicate the availability of support as it is pointed out that informal carers themselves may need financial, emotional or other support from the formal support network (Katbamna, Ahmad, Bhakta, Baker, and Parker, 2004). For example, Littlewood and Dein (2016) noticed that South Asian extended families themselves might even be unsupported and may be dependent on social services. Moreover, family carers with support needs are often reluctant to seek support from the social network considering the family reputation. Furthermore, senior women become unsupported and unprotected upon the death of their husband (Katbamna et al., 2004). Therefore, the stereotypes that care needs of the community people will be met by the kinship network may lead the older population to the exclusion from the existing services.

The 'care' in the South Asian family is organized under the myth that a family is a collective unit where 'caring' is a social obligation of the family members. The kinship network in the South Asian region is distinct from the other regions of the world (Guha, 1987). This kinship system comprises of evolving relations with the members of kin with whom the boundaries of duties and responsibilities are negotiated in terms of obligations and expectations. The cultural norms clearly define the relationships among the family members, and thereby, the roles and responsibility of every member are also fixed (Littlewood \& Dein, 2016). The elders among the South Asians hold a 'respected' position in the kinship system, and they are expected to be cared of by the immediate kin at home (Purewal \& Jasani, 2017).

\section{Objectives of the study}

The aim of the study was to explore the experiences of informal care services received by older people with long term illness (LTI) living in the Sylhet region of Bangladesh. The specific objectives were:

www.scirj.org

(C) 2019, Scientific Research Journal

http://dx.doi.org/10.31364/SCIRJ/v7.i11.2019.P1119729 
1. To know their physical and mental health condition as affected by the LTI

2. To explore their experiences of informal caring as provided by the family members

3. To identify some challenges that hampers their relationship with family members and informal caring.

\section{Definition of the concepts}

For the purposes of study the following definition of concepts were used:

\section{Long term illness (LLTI)}

LLTI is defined by the Office for National Statistics, UK (2006) as any long term illness, health problem or disability which limits daily activities or work, including problems due to old age. In this study, LLTI was used to refer the following long term illness e.g. cardiovascular disease, stroke survivor, cancer patient, diabetes, asthma or arthritis etc. that affect on the physical and mental health condition of persons.

\section{Informal care}

Informal care is used to refer care by family members who provide unpaid assistance for their dependent relatives who live in the community (Heaton, 1999: 759). According to the English Legislation, carer is often used for informal carer to distinguish them from paid care workers which identify a person aged 16 or over who provides or intends to provide a substantial amount of care on a regular basis for an adult or a disabled child. The person may or may not be a relative and may or may not be living with the person whom they are caring (DH, 2005:22). In this study informal care was used to refer any type of unpaid assistance provided by family members to older people to carry out his/her daily activities including support to take bath, taking medicine, going to visit doctor or hospital, going to shop or visiting relative's house, religious centres etc.

\section{Older people}

Older people were used to identify in the line with the national policy on aging (2013) of Bangladesh as those male or female persons belong to age group of 60 years and over. According to the Bangladesh of BBS report (2015) it is shown that the share of older population is highest in the Dhaka Division (26.04 per cent) and lowest in the Sylhet Division (7.89 per cent).

\section{Methodology of the study}

The study was based on primary sources of data; however the secondary data i.e. official documents, books, journals, policy papers etc. were used to conduct the study. The study followed qualitative research approach and the case study method to generate sufficient primary data. This method was chosen because it was thought more appropriate to gain better understanding of the health condition, caring requirements and care receiving experiences of older people including informal care services provided by their family members. The in-depth interviews were undertaken with semi-structured interview schedule to collect necessary information to address the research objectives. In addition, two focus group discussions were arranged with six to eight participants in each group to substantiate the interview data. 


\section{The study area and population}

The Sylhet City Corporation (SCC) was selected purposively as the area of study. It was chosen because, the growth of urbanization is much higher than some other major cities of the country except the capital city and it is distinctly disadvantaged in terms of health, education and women's empowerment (UNICEF, 2009). Therefore, it is important to understand the health condition of older people and their informal caring experiences.

\section{Sampling procedure}

Both purposive and snowball sampling method was used to gain access to the respondents. A multi-stage sampling technique was employed to recruit appropriate samples. The Sylhet City Corporation (SCC) area was selected purposively for conducting the study. Primarily three (03) wards were selected purposively for recruiting research participants. Semi-structured interviews were conducted with twenty-one samples (21) taking twelve (11) male informants and ten (10) female informants. In addition, two FGDs were conducted with another two wards of the SCC. The inclusion criteria for sampling were set up in the following way:

1. The age of older people was 65 years and over and had been suffering from any one or more of the following long term illness e.g. cardiovascular disease, stroke survivor, cancer patient, diabetes, asthma or arthritis for the last two years.

2. The older people with those long term illness require others help to carry out his/her daily activities e.g. support to take bath, taking medicine, going to visit doctor or hospital, going to shop or visiting relative's house, religious centres or participate in the community events including marriage ceremony or pleasure trip etc.

3. The older people with having above mentioned illness live in the Sylhet city corporation area for the last two years with his family and cared by spouse or son or daughter or in- laws relatives.

4. The older people or his/her family carer can speak in Sylheti dialect of Bangla or standard Bangla language.

\section{Data collection}

The interview protocol was designed in the line with established studies e.g. Rodehaver (2008). Open ended interview guideline were prepared and used to lead the interview session smoothly (Kerr and Smith, 2001). For focus group discussions, the ground rules were negotiated with the participants to make the discussions interactive. In many cases, questions were open ended with a number of sub questions, which were substituted for the following three main research questions:

1. What types of health problems do the older people face?

2. What types of informal care do they get from the family members and what challenges do they face?

3. Do they experience any problem of relationship that hampers the informal care?

On an average the duration of in depth interviews were 45 minutes to 1 hour and the FGDs were 2 hours to 2 hours and 30 minutes in length. The researcher along with two data collectors carried out the interviews and conducted the FGDs to understand health issues of older people with LTI, informal care and relationship with informal carer etc. The data collection process was ended when the interview or FG reached at the saturation point when no new data were found and the participants repeated the same information. The data collection period was six month from March, 2017 to September, 2017. A full transcription i.e. verbatim method was followed and the audio recorded interviews were first written in Bangla and then translated and typed into English. 


\section{Ethical considerations}

Since, there were no any institutional review board (IRB) to direct the research process in the Shahjalal University of Science \& Technology, the researchers followed the ethical guidelines offered by Miles and Huberman (1994). Participation in the study was entirely voluntary and relied on the ethical principle of informed consent. At the start of interview and FGD, the study purpose and nature was explained. They were asked to choice whether they can participate or not to participate and those who wanted to participate the written consent was taken from those who can write and verbal consent was taken from those who did not know how to put signature. It was also explained that while the anonymity and confidentiality of individuals was preserved that their verbatim may be published without using their actual name.

\section{Data analysis}

The in depth interviews and FGDs were audio recorded with the permission of the respondents. The verbatim recordings were transcribed and translated into English by the researcher and two research assistants. The data were read, re-read and taken for open coding and thematic analysis. From the original data codes were generated in terms of the various concepts and issues and then selective coding was conducted to systematically analyze the data and identify the most prominent themes. The 'iterative' analysis process was followed and a particular attention was given to choosing and using the quotations which is most relevant to the specific issue (Srivastava \& Hopwood, 2009). Data saturation was achieved at the end of interview sessions when the information was repeated across the data and no new findings were emerged.

\section{Result and discussion}

\section{General health condition}

In order to understand the LTI of Bangladeshis, there was an attempt to investigate their physical health status. The study reveals that most Bangladeshi older people with LTI have experienced major diseases like diabetes, hypertension, stroke, paralysis, cardiovascular diseases, arthritis etc. They have been suffering from one or more of the above diseases which seriously affect their physical and mental wellbeing. The following excerpts echo the issue:

I've been suffering from many types of diseases. These are stroke, hypertension, diabetic, arthritis. The diseases are working like an interrelated fashion and make the body so weaker that I can't walk. I don't have had sound sleep at night. (Women, 73 years)

I have a long history of diabetes more than 16 years. The sugar level fluctuates frequently. Previously I could understand by body condition whether it is rising or going lower. Now I can't. (Man, 75 years)

The data also shows that majority of them experienced one or more risky incidents which required treatment in the hospital. The following extracts clarify the vulnerability of their health:

I was bound to stay at hospital for seven days. The whole left side of the body was paralyzed. I cannot take seat or stand. All the time I had to lie in bed. Even I can't change body side. My mouth was affected and can't speak; often I was burst into tears.

I was totally bed ridden for at least three months and I could not take food by myself. Somebody's help was necessary to take food and other natural activities i.e. taking bath, toilet etc. It seems I would no longer live. (Man, 75 years)

Www.scirj.org 
I had slept as a sound person but when I got up I found half of the body paralyzed! Even I could not make movements or stand! I could not speak properly. After that incident my left hand was paralyzed for the last three years.

I am suffering from arthritis. There is pain all over in the body. I feel pain in waist and can't stand or walk. The bone of waist has been decayed. (Women, 63 years)

The study findings demonstrate that their mental health has been adversely affected due to LTI. The following narratives raised the issue:

My sleeping at night is hampered due to diseases, especially for asthma and arthritis; there is pain all over in body. Sometimes I feel much anger to anybody without reason. I can't control my anger when somebody disagrees with me. (Woman, 73 years)

Life sometimes seems very longer and very hard to bear. But nothing to do; we cannot die by ourselves! Sometimes I feel depressed and don't like to talk with my son or daughter in law. (Man, 77 years)

Now I feel very lonely! My wife had been passed away! But there were days when many people come to me to serve their purposes. They gathered me! Now even my children don't have time to stay with me. (Man, 75 years)

I feel stress due to disease. Sometimes I feel insomnia and it creates much tension. I feel I am tensed for something but cannot leave it. (FG, Man, 65 years)

Stress and tensions had broken my confidence. My husband is not alive. Elder son and his wife left us; they did not support me. One daughter is widow; she with her one boy lives with me. I am worried about future e.g. how to run the family and carry my medical cost. (FG, Woman, 70 Years).

\section{Informal caring and strain family relationship}

The study demonstrates that not all older people are cared well by their family members and a significant number of them get some sort of negative experiences. However, traditional expectations of family care presume that it is unproblematic and the best form of care for older people with LTI. This study raises a sensitive issue of strained relationships. There is some evidence of cold relationships with son-in-law or daughter-in-law. The following narratives point out the issue:

Here I live with my elder son's family. As I am older and physically ill, many times my other sons and daughters come here and stay for a few days. But my daughter-in-law (wife of elder son) does not take it positively. She tells it negatively to my son which sometimes create tensions in the family. (FG, Man, 70 Years)

Sometimes I feel hot-tempered when the son or daughters do not work according to my will. They do not have time to sit down by my side. Now it seems that I am not their father! I am an older person! (Man, 75 Years)

When other people comes to our house, my son and daughter in-law gives much time to arrange food for them; gossiping with them etc. But if I call them to go to doctor, they do not have time to go there. These are painful to me and I can't tolerate these. (Man, 75 Years) 
The study findings also reveal that the mental health of older people is challenged and severely affected by the death of a spouse. In our Bangladeshi society, the informal caring is primarily done through the network of kinships and particularly by the spouses. In case of the death of a spouse, the scope of caring in the family is shrunk significantly. Consequently, the old people face loneliness, insecurity, and emotional imbalances created due to the death of spouse:

My life could not become so miserable if he (husband) had alive! He could maintain the family expenses, keep children on right track. Now I am a widow (lari beti). Nobody takes care of me or values me. Who will take me to the doctor and bear my expenses? (Woman, 70 years)

I am as unlucky as my wife has passed away! At this time her nourishment could be fruitful. She would take me to the bathroom, massage my body and give condolence and courage. Now it is like that I am a wingless bird! (Man, 75 years)

You know woman integrates the family members which makes the family bond strong. $\quad$ Due to the death of my wife a gap is created between the children and me. However, the daughters are responsive to me when I call them but they are not much attentive to me. (Man, 67 years).

The study shows that cooking and food serving is also important for caring the older people. It is evident that older people with diabetes, gastric or hypertension require some changes in the food habit which in turn create a gap in choices or food preferences between older people and other family members. The following narratives clarify the issue:

I cannot take hard rice. The women who cook rice are careless! They don't hear my advice. They don't realize my situation. (Man, 65 years)

My family members like chilly in cooking food items e.g. in fish or chicken curry. My stomach does not tolerate such kind food. They don't care it. It seems that they are just offering food but don't want to know whether you take it or not. (FG, Man, 70 years)

\section{Financial crisis and family relationship}

The study findings suggest that the majority of the older people recognized that their health care opportunity had been contracted due to the poverty of the family and it affects their physical and mental health. The following extracts clarify the situation:

About six months ago, I went to Sylhet Osmany Hospital for treatment and got better by taking medicine according to the doctor's advice. Now I have no money to buy food, let alone medicine! (Women, 63 years)

I am passing tough times! My only son is not in the right track! He did not earn. I am bound to live on loan and peoples charity (lillah). Sometimes I am bound to starve because I do not have money to buy food! (Women, 63 years)

Majority of people migrated from rural to urban area live in a rented property and the amount of rent is much high and face financial pressure to support older people with LTI. One carer clarifies the issue:

I struggle hard to pay the house rent, food, education and clothing of family members, how can I manage the special treatment cost and other needs of him (parent with LTI)? (FG, Carer, 45 Years) 
We live in a poor housing because we have no ability to rent good houses. My daughter-in-law and grand children also face troubles to live in such houses. I struggle hard to use upstairs. (Man, 73 years)

\section{Overcrowded housing and family relationship}

The study also reveals that accommodation and housing, a crucial factor for a significant number of participants living in the joint or extended family. It is shown that majority of the participants do not have appropriate housing facilities to meet current their health condition. They face significant problems in winter when there are no hot water facilities available. In case of the washroom, arrangements are not up to their demand. The following extracts echo the issue:

There is no handle near high commode in the bathroom; so I feel troubles there to sit. The basement of high commode is higher, and so I do not feel comfortable there. (Man, FG, 65 years)

In winter I feel many problems, can't even take ablution (oju) and bath due to paralysis. I use thayammum (the alternative to ablution) for performing prayer salath. It would be good for me if anybody gives hot water and helps me in doing oju. (Man, 75 years)

We live in a rented house where there is no ventilator and during summer we struggle hard for load shedding of electricity. (Man, 65 years)

We are six members living in a small two bedroom house. The rooms are dark and one washroom cum bathroom. I face troubles to share with bou ma (daughter in-law) and grand children. (Man, 70 years)

\section{The risk of older neglect and abuse}

The study reveals that majority of older people with LTI feel a sense of low self- esteem and perception of neglect due to their long term illness and dependency on informal carer. The following narratives clarify the issue:

I am just living mercy of my son and daughter in-law. They sometimes feel bore and do not response promptly when I call them. They thought I always call without reason. (Man, 75 years)

People do not have interest on older people with LTI. They thought the situation of us would be same as no possible sign of improvement and avoid us to hear our health problems. (Women, 73 years)

The incident of abuse in the family is not less common among the Bangladeshi older people, although these are unreported and are consciously hidden. One participant with heart disease, arthritis and hypertension narrated his experience of abuse in the family:

My boy is derailed! He is addicted to drugs. To whom I would cry! He is young enough but does not earn money. He sometimes beat me and oppress for money. (Woman, 70 years)

Another participant shares his experience of how he becomes angry and does not control himself in the face of psychological abuse inside the family: 
My daughter in-law is now guardian and leader in my family. She has got power from her husband. My son obeys his wife and sometimes misbehaves with us. (Man, 72 Years).

Sometimes I feel my body is burning to see activities of my daughter-in-law. He shows negative attitude towards us. She quarrelled with us about spending money for treatment and buying medicine. (Man, 77 Years).

However, the study provides some valuable information concerning the informal care of older people in Bangladesh, it could not be generalised due to limited geographic coverage and small number of samples etc. The findings generated in the study could help policy makers and service providers working with older people in many ways as it points out that although there remain centrality of the family in caring for older people with LLTI, they face multiple challenges including relationship with family members, death of the spouse, financial pressure, lack of housing amenities etc. increases the risk of older abuse and neglect in the society. For example, a significant issue for the participants in the study was strain relationship with the carer e.g. family members. Having different expectations of how much care can realistically be given is a source of tension and can lead to strained family relationships. Tensions and stress accumulate when LTI, the cost of living and treatment or cultural barriers mean people are unable to maintain a peaceful life. However, the scope of this study cannot address all the barriers faced by Bangladeshi older people with LLTI, it focus on the physical and mental ill health, relationship with son or daughter -in law, food habit and financial capacity of the family to provide care. As people's mental health is adversely affected by LLTI, steps should be taken to raise consciousness about LLTI and how to maintain and improve their mental health. It would be helpful to counsel them how to adapt with LLTI, managing stress and controlling emotions, but service providers need to become culturally competent and outreach to the community in order to address the multiple factors involved. The study broke new ground in highlighting an issue which is highly taboo in the Bangladeshi community. There is evidence that some widowed older people with LLTI are vulnerable to neglect and abuse. Although the findings cannot be generalised, there was evidence of severely strained relationships where older people were treated unkindly and possibly abused by family members. However, they suffer in silence because of the shame for themselves and their family. Therefore, more attention needs to be paid to the risk of older neglect and abuse in the urban context of Bangladesh. This study shows that the ability of the family to provide care in urban areas is limited and challenged by some reality of everyday life e.g. poverty of the family, rented house and inappropriate housing condition, death of spouse etc.

\section{Conclusion}

This study provides some valuable evidence that older people with LLTI experience multiple disadvantaged position in the context of Bangladesh. They face multi-dimensional problems, characterized by deteriorating health conditions, lack of care provided by family members and strain relationship with informal carers. The data also highlight a continuous cycle of marginalisation resulting from the interplay of LLTI, poverty, and other socio-cultural factors. Although like other Bangladeshi population groups, Sylheti people want to live in the extended family and expect to be cared for within it, poverty, overcrowded housing and the high expenses of treatment make this problematic. Families face a considerable burden of care, but contrary to popular assumptions, this study shows that family care is stressful and not always a positive experience. Therefore social safety net needs to be strengthened for the older people of the country. 


\section{References}

Barnes, M. (2005). Social exclusion in Great Britain: An empirical investigation and comparison with the EU. Aldershot, Belgium: Ashgate.

Bangladesh, U. N. I. C. E. F. (2009). Situation Assessment and Analysis of Children and Women. UNICEF Bangladesh, Dhaka, 8385.

Department of Health (2005). Carers and Disabled Children Act 2000 \& Carers Equal Opportunities Act 2004. Combined Policy Guidence. Department of Health, London.

Duffy, K. (1995). Social exclusion and human dignity in Europe. Strasbourg: Council of Europe.

Gardner, K. (2002). Narrative, Age and Migration: Life Histories and the Life Course amongst Bengali Elders in London. Oxford: Berg.

Guha, R. (1987). Chandra's Death. In R. Guha (Ed.), Writings on South Asian History and Society (pp. 135-165). New Delhi: Oxford University Press.

Harper, S., \& Levin, S. (2005). Family care, independent living and ethnicity. Social Policy and Society, 4(2), $157-169$.

Heaton, J. (1999). The gaze and visibility of carers: a Foucauldian analysis of the discourse of informal care. Sociology of health and Illness 21 (6), 759-777.

Hyman, I. (2001). Immigration and health (Health Policy Working Paper Series, Working Paper 01-05, Ottawa: Canada). Retrieved from http://citeseerx.ist.psu.edu/viewdoc/download?doi=10.1.1.600.4038\&rep=rep1\&type=pdf

Katbamna, S., Ahmad, W., Bhakta, P., Baker, R., \& Parker, G. (2004). Do they look after their own? Informal support for South Asian carers. Health \& social care in the community, 12(5), 398-406.

Kumar, S. V. (1995). Challenges Before the Elderly: An Indian Scenrio. New Delhi: MD Publications Pvt. Ltd.

Levitas, R. (1998). The inclusive society?: social exclusion and New Labour. London: MacMillan Press Ltd.

Littlewood, R., \& Dein, S. (2016). Carers and families: life and suffering among Bangladeshi psychiatric patients and their families in London-an interview study 3. Anthropology \& medicine, 23(1), 54-70.

Miles, M.B., and Huberman, A. M., (1994). An Expanded Sourcebook: Qualitative Data Analysis. Thousand Oaks, CA: Sage.

Noh, S., Beiser, M., Kaspar, V., Hou, F., \& Rummens, J. (1999). Perceived racial discrimination, depression, and coping: A study of Southeast Asian refugees in Canada. Journal of Health and Social Behavior, 193-207.

Office of National Statistics. (2006). Health: Limiting Illness. Retrieved from

http:/hwvw.statislics.gov.uk/CCI/nugget.asp?ID=1326\&Pos=1\&ColRank=2\&Rank=672

Purewal, N., \& Jasani, R. (2017). South Asian women elders and everyday lives of 'care in the community'in Britain: the neoliberal turn in social care and the myth of the family. South Asian Diaspora, 9(2), 111-127. doi:10.1080/19438192.2017.1339381

Rodehaver, C. L. (2008). A Study of family primary caregivers for adults with a severe mental illness. ProQuest.

Kerr S. M., \& Smith, L. N. (2001). Stroke: an exploration of the experience of informal caregiving. Clinical rehabilitation, $15(4), 428-436$.

Srivastava, P., \& Hopwood, N. (2009). A practical iterative framework for qualitative data analysis. International journal of qualitative methods, 8(1), 76-84.

Tong, H. M., Lai, D. W., Zeng, Q., \& Xu, W. Y. (2011). Effects of social exclusion on depressive symptoms: elderly Chinese living alone in Shanghai, China. Journal of cross-cultural gerontology, 26(4), 349-364.

Victor, C., Martin, W., \& Zubair, M. (2012). Families and caring amongst older people in South Asian communities in the UK: a pilot study. European Journal of Social Work, 15(1), 81-96.

Victor, C., \& Zubair, M. (2015). Expectations of care and support in old age by Bangladeshi and Pakistani elders. In U. Karl \& S. Torres (Eds.), Ageing in Context of Migration (pp. 108-118). London: Routledge.

Wilkinson, R. G. (1996). Unhealthy societies: the afflictions of inequality. London: Routledge.

Www.scirj.org 
